\title{
Hyperforin Inhibits Cell Growth by Inducing Intrinsic and Extrinsic Apoptotic Pathways in Hepatocellular Carcinoma Cells
}

\author{
I-TSANG CHIANG ${ }^{1,2,3 *}$, WEI-TING CHEN ${ }^{4 *}$, CHIH-WEI TSENG ${ }^{5}$, YEN-CHUNG CHEN ${ }^{2,6}$, YU-CHENG KUO ${ }^{7}$, \\ BI-JHIH CHEN ${ }^{8}$, MAO-CHI WENG ${ }^{9}$, HWAI-JENG LIN ${ }^{10,11 \#}$ and WEI-SHU WANG ${ }^{2,12,13 \#}$ \\ Departments of ${ }^{1}$ Radiation Oncology, ${ }^{6}$ Pathology, and ${ }^{13}$ Medicine, and \\ ${ }^{2}$ Cancer Medical Care Center, National Yang-Ming University Hospital, Yilan, Taiwan, R.O.C.; \\ ${ }^{3}$ Department of Radiological Technology, \\ Central Taiwan University of Science and Technology, Taichung, Taiwan, R.O.C.; \\ ${ }^{4}$ Department of Psychiatry, Zuoying Branch of Kaohsiung Armed Forces General Hospital, \\ Kaohsiung, Taiwan, R.O.C.; \\ ${ }^{5}$ Division of Gastroenterology, Department of Internal Medicine, Dalin Tzu Chi Hospital, \\ Buddhist Tzu Chi Medical Foundation, Chia-Yi, Taiwan, R.O.C.; \\ ${ }^{7}$ Radiation Oncology, Show Chwan Memorial Hospital, Changhua, Taiwan, R.O.C.; \\ ${ }^{8}$ Department of Laboratory Medicine, Changhua Christian Hospital, \\ Changhua Christian Medical Foundation, Changhua, Taiwan, R.O.C.; \\ ${ }^{9}$ Institute of Nuclear Energy Research, Atomic Energy Council, Taoyuan, Taiwan, R.O.C.; \\ ${ }^{10}$ Department of Internal Medicine, Division of Gastroenterology and Hepatology, College of Medicine, \\ School of Medicine, Taipei Medical University, Taipei, Taiwan, R.O.C.; \\ ${ }^{11}$ Department of Internal Medicine, Division of Gastroenterology and Hepatology, \\ Shuang-Ho Hospital, New Taipei, Taiwan, R.O.C., \\ ${ }^{12}$ National Yang-Ming University School of Medicine, Taipei, Taiwan, R.O.C.
}

\begin{abstract}
The aim of the present study was to investigate the antitumor effect and mechanism of action of hyperforin in hepatocellular carcinoma (HCC) SK-Hepl cells in vitro. Cells were treated with different concentrations of hyperforin for different periods of time. Effects of hyperforin on cell viability, apoptosis signaling, and expression of anti-apoptotic and proliferative proteins [cellular FLICE-like inhibitory protein
\end{abstract}

\footnotetext{
*\#These Authors contributed equally to this study.

Correspondence to: Professor Wei-Shu Wang, M.D., Ph.D., Department of Medicine, National Yang-Ming University Hospital, No.152, Xinmin Rd., Yilan City, Yilan County 260, Taiwan, R.O.C. Tel: +886 39325192 ext. 1621, Fax: +886 39351838, e-mail: 11313@ymuh.ym.edu.tw and Hwai-Jeng Lin, M.D., Department of Internal Medicine, Division of Gastroenterology and Hepatology, Shuang-Ho Hospital, No.901, No. 291 Zhongzheng Rd. Zhonghe District, New Taipei City, 23561, Taiwan, R.O.C. Tel: +886 52648000 ext: 5333, Fax: +886 52838370, e-mail: buddhistlearning@gmail.com
}

Key Words: Hepatocellular carcinoma, hyperforin, apoptosis.
(c-FLIP), X-linked inhibitor of apoptosis protein (XIAP), myeloid cell leukemia 1(MCL1), and cyclin-D1] were investigated by 3-(4,5-dimethylthiazol-2-yl)-2,5-diphenyltetrazolium bromide assay, flow cytometry, and western blotting. Hyperforin significantly inhibited cell viability and expression of anti-apoptotic and proliferative proteins. We also found that hyperforin significantly induced accumulation of cells in sub$G_{1}$ phase, loss of mitochondrial membrane potential, and increased levels of active caspase-3, and caspase-8. Taken together, our findings indicate that hyperforin triggers inhibition of tumor cell growth by inducing intrinsic and extrinsic apoptotic pathways in HCC SK-Hepl cells.

Apoptosis, or programmed cell death, can be divided into initiation, effector, and degradation phases (1). The process of apoptosis is activated by a variety of physiologic and nonphysiological stimuli through extrinsic and intrinsic pathways. Morphological characteristics of apoptosis include cell shrinkage, surface blebbing, chromatin condensation, chromosomal DNA fragmentation, and formation of apoptotic bodies (2). Anticancer agents kill cancer cells by inducing extrinsic and intrinsic apoptotic pathways. Tumoricidal effects 
of anticancer agents can be inhibited by anti-apoptotic proteins in cancer cells and these result in treatment failure (3). Hepatocellular carcinoma (HCC) is among the most common lethal types of cancer worldwide and resistant to conventional chemotherapy through high expression of antiapoptotic proteins such as cellular FLICE-like inhibitory protein (c-FLIP), myeloid cell leukemia 1 (MCL1), and Xlinked inhibitor of apoptosis protein (XIAP). Therefore, development of agents facilitating induction of apoptosis may be beneficial for patients with HCC (4-7).

Antidepressants can improve mood disorders, such as major depression, anxious disorder, and dysthymia by altering the reuptake of neurotransmitters at the synapse. Several recent studies indicated that antidepressants not only alleviate mood disorders but also influence tumor progression $(8,9)$. Frick et al. suggested that antidepressants are able to modulate apoptotic mechanism and activate antitumor immunity to inhibit tumor growth (8). Fluoxetine, a selective serotonin reuptake inhibitor, has been found to suppress tumor growth by inducing apoptosis of HCC and glioblastoma cells $(10,11)$. Fang et al. suggested that mirtazapine, a noradrenergic and specific serotonergic antidepressant, increases expression of interlukin-12 (IL12) and interferon-gamma (INF $\gamma$ ) in addition to enhancing $\mathrm{CD}^{+}$ and $\mathrm{CD}^{+} \mathrm{T}$-cell infiltration within cancer tissue, and inhibits tumor growth in colorectal cancer in vivo (12).

Hyperforin, a polyprenylated acylphloroglucinol isolated from St. John's wort, has antidepressant activity by blocking the reuptake of serotonin, dopamine, noradrenaline, $\gamma$ aminobutyric acid, and glutamate. In addition, hyperforin has antitumor effect in various types of cancer cells (13). Donà et al. found that hyperforin inhibits expression of metastasisassociated proteins, such as urokinase-type plasminogen activator, and matrix metalloproteinases (MMPs) 2 and 9 while reducing lung metastasis (14). Hyperforin also acts as an apoptotic inducer to promote caspase-mediated apoptosis in breast cancer and myeloid tumor cells $(15,16)$. However, whether hyperforin can inhibit tumor cell growth by inducing apoptosis in HCC is not known. The aim of the present study was to investigate the antitumor effect and mechanism of action of hyperforin in HCC SK-Hep1 cells by 3-(4, 5dimethylthiazol-2-yl)-2,5-diphenyltetrazolium bromide (MTT), flow cytometry, and western blotting.

\section{Materials and Methods}

Chemicals and agents. Dulbecco's modified Eagle's medium (DMEM), fetal bovine serum (FBS), L-glutamine, and penicillinstreptomycin (PS) were bought from Gibco/Life Technologies (Carlsbad, CA, USA). Propidium iodide (PI), CaspGLOW ${ }^{\mathrm{TM}}$ Fluorescein Active Caspase-3 Staining Kit, and CaspGLOW ${ }^{\mathrm{TM}}$ Red Active Caspase-8 Staining Kit were bought from Biovision (Mountain View, CA, USA). 3,3'-Dihexyloxacarbocyanine Iodide ( DiOC $_{6}$ ) was obtained from Enzo Life Sciences (Farmingdale, NY, USA).
Hyperforin and MTT were purchased from Sigma-Aldrich (St. Louis, MO, USA). RNase was obtained from Fermentas (St. Leon-Rot, Baden-Württemberg, Germany). Primary antibodies to c-FLIP and cyclin D1 were bought from Cell Signaling Technology (Beverly, MA, USA). Primary antibody to XIAP was obtained from Thermo Fisher Scientific (Fremont, CA, USA). Primary antibody to $\beta$-actin was purchased from Santa Cruz Biotechnology (Santa Cruz, CA, USA). Primary antibody to MCL1 was bought from BioVision (Milpitas, CA, USA). Secondary antibodies were bought from Jackson ImmunoResearch (West Grove, PA, USA).

Cell culture. SK-Hep1 cells were obtained from Professor JingGung Chung at the Department of Biological Science and Technology, China Medical University, Taichung, Taiwan. Cells were cultured in DMEM containing 10\% FBS, $2 \mathrm{mM}$ L-glutamine, and PS $(100 \mathrm{U} / \mathrm{ml}$ and $100 \mu \mathrm{g} / \mathrm{ml})$ at $37^{\circ} \mathrm{C}$ in a humidified atmosphere containing $5 \% \mathrm{CO}_{2}(17)$.

MTT assay. SK-Hep1 cells were plated into 96-well plates at $3 \times 10^{4}$ cells/well and incubated overnight. Cells were treated with different concentration of hyperforin $[0-10 \mu \mathrm{M}$ in $0.1 \%$ dimethyl sulfoxide (DMSO)] for 24 or $48 \mathrm{~h}$. The effects of hyperforin on cell viability was evaluated with MTT assay, as described by Chen et al. (18).

Analysis of sub-G $G_{1}$ population. SK-Hep1 were plated into 12-well plates at $2 \times 10^{5}$ cells/well and incubated overnight then treated with $5 \mu \mathrm{M}$ hyperforin for different time intervals. Cells were harvested by centrifugation and fixed with $70 \%$ ethanol and incubated overnight at $-20^{\circ} \mathrm{C}$. Cells were washed twice with phosphatebuffered saline (PBS) and then re-suspended in $500 \mu \mathrm{l}$ of PI working solution (40 $\mu \mathrm{g} / \mathrm{ml} \mathrm{PI,} 100 \mu \mathrm{g} / \mathrm{ml} \mathrm{RNase,} \mathrm{and} 1 \%$ Triton $\mathrm{X}-100$ in PBS) in the dark at room temperature for $1 \mathrm{~h}$. Analysis of cell-cycle distribution was performed by using flow cytometry (FACS101, Becton Dickinson FACScan, Franklin Lakes, NJ, USA) as described by Ma et al. (19).

Detection of active caspase-3. SK-Hep1 were plated into 12-well plates at $2 \times 10^{5}$ cells/well and incubated overnight then treated with $5 \mu \mathrm{M}$ hyperforin for different time intervals. Cells were collected by centrifugation and washed with PBS, and re-suspended in $300 \mu \mathrm{l}$ of $\operatorname{Asp}\left(\mathrm{OCH}_{3}\right)$ - $\mathrm{Glu}\left(\mathrm{OCH}_{3}\right)$-Val-Asp $\left(\mathrm{OCH}_{3}\right)$-fluoromethyl ketone (DEVD-FMK), conjugated to fluorescein isothiocyanate (FITC) working solution ( $1 \mu \mathrm{l}$ FITC-DEVD-FMK in $300 \mu \mathrm{l}$ PBS) for $0.5 \mathrm{~h}$ at $37^{\circ} \mathrm{C}$ in a humidified atmosphere containing $5 \% \mathrm{CO}_{2}$. Cells were then harvested by centrifugation and washed twice with wash buffer and then re-suspended in $300 \mu \mathrm{l}$ of wash buffer. Detection of active caspase-3 was performed by using flow cytometry (FACS101, Becton Dickinson FACScan; Becton Dickinson, Franklin Lakes, NJ, USA) with FL-1 channel (20).

Detection of mitochondrial membrane potential (MMP). SK-Hep1 were plated into 12 -well plates at $2 \times 10^{5}$ cells/well and incubated overnight then treated with $5 \mu \mathrm{M}$ hyperforin for different time intervals. Cells were collected by centrifugation and washed with PBS, and resuspended in $\mathrm{DiOC}_{6}$ working solution $\left(4 \mu \mathrm{M} \mathrm{DiOC}{ }_{6}\right.$ in $500 \mu \mathrm{lBS})$ in the dark at $37^{\circ} \mathrm{C}$ for $0.5 \mathrm{~h}$. Analysis of MMP was performed using flow cytometry (FACS101, Becton Dickinson FACScan) as described by Hsu et al. (21).

Detection of active caspase- 8 . SK-Hep 1 were plated into 12 -well plates at $2 \times 10^{5}$ cells/well and incubated overnight then treated with 
$5 \mu \mathrm{M}$ hyperforin for different time intervals. Cells were collected by centrifugation and washed with PBS, and re-suspended in $301 \mu \mathrm{l}$ of IETD-FMK conjugated to sulfo-rhodamine (Red-IETD-FMK) working solution $(1 \mu \mathrm{l}$ Red-IETD-FMK in $300 \mu \mathrm{l}$ PBS $)$ for $0.5 \mathrm{~h}$ at $37^{\circ} \mathrm{C}$ in a humidified atmosphere containing $5 \% \mathrm{CO}_{2}$. Cells were harvested by centrifugation and washed twice with wash buffer and then re-suspended in $300 \mu \mathrm{l}$ of wash buffer. Detection of active caspase- 8 was performed by using flow cytometry (FACS101, Becton Dickinson FACScan) with FL-2 channel (22).

Western blotting assay. SK-Hep1 cells $\left(3 \times 10^{6}\right)$ were plated into 10 $\mathrm{cm}$ diameter dishes and incubated overnight then treated with $5 \mu \mathrm{M}$ hyperforin for different time intervals. Lysis buffer $(50 \mathrm{mM}$ Tris$\mathrm{HCl} \mathrm{pH} \quad 8.0,120 \mathrm{mM} \mathrm{NaCl}, 0.5 \% \quad \mathrm{NP}-40$, and $1 \mathrm{mM}$ phenylmethanesulfonyl fluoride) was used to extracted total protein from cells in each group. Protein levels of c-FLIP, XIAP, MCL1, and cyclin D1 were determined with western blotting assay as described by Lai et al. (23). ImageJ software (National Institutes of Health, Bethesda, MD, USA) was used for quantification of protein bands.

Statistical analysis. Difference of means between experimental and control groups was tested using Student's $t$-test and considered significant with $p$-value of 0.05 or less. Data are presented as the mean \pm standard error.

\section{Results}

Hyperforin induces cytotoxicity in SK-Hepl cells. Hyperforin significantly reduced cell viability in SK-Hep1 cells in a time-dependent manner. Figure 1 shows that hyperforin treatment $(2.5-10 \mu \mathrm{M})$ significantly reduced cell viability by $29-55 \%$ and $54-74 \%$ at $24 \mathrm{~h}$ and $48 \mathrm{~h}$ as compared to controls, respectively.

Hyperforin induces apoptosis of SK-Hepl cells. Accumulation of cells at sub-G1 phase and activation of casapse-3 and are correlated with apoptosis $(24,25)$. In order to verify whether hyperforin induces apoptosis of SK-Hep1 cells, detection of active caspase- 3 and the sub- $\mathrm{G}_{1}$ cell population were performed by using flow cytometry. Figure 2 indicates hyperforin significantly increased the sub- $\mathrm{G}_{1}$ cell population and level of active caspase- 3 in a time-dependent manner as compared to the control.

Hyperforin induces apoptosis through intrinsic and extrinsic pathways in SK-Hepl cells. Loss of MMP is a characteristic of the intrinsic apoptotic pathway while activated caspase- 8 is a specific marker of the extrinsic apoptotic pathway (26, 27). Detection of MMP and active caspase- 8 was used to evaluate the mechanism of hyperforin-induced apoptosis of SK-Hep1 cells. Figure 3A shows that hyperforin significantly enhanced loss of MMP as compared to controls at $24 \mathrm{~h}$ and $48 \mathrm{~h}$. Figure 3B indicates that hyperforin significantly induced activation of caspase- 8 in a time-dependent manner as compared to controls.

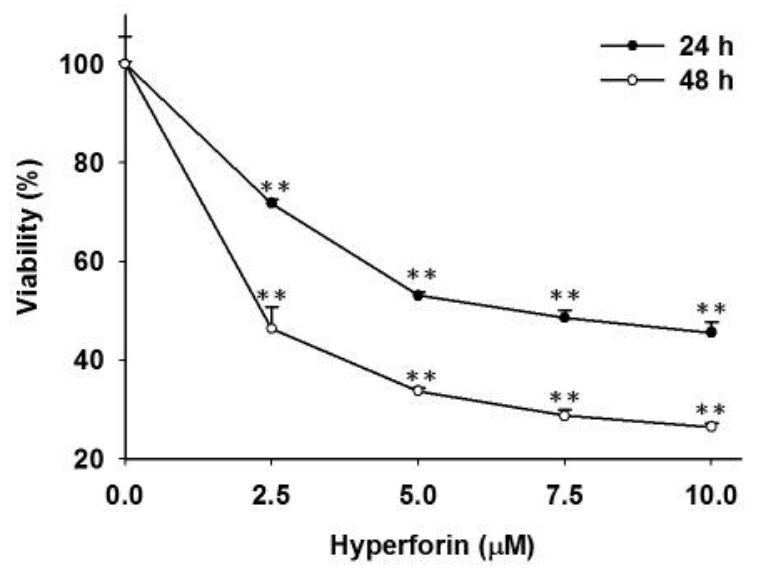

Figure 1. The effects of hyperforin on viability of SK-Hep1 cells. Cells were treated with different concentrations (in $0.1 \%$ dimethyl sulfoxide) of hyperforin for 24 and $48 \mathrm{~h}$. Cell viability was evaluated with the MTT assay. ${ }^{*}$ Significantly different at $p<0.01$ compared to controls.

Hyperforin inhibits expression of anti-apoptotic and proliferative proteins in SK-Hepl cell. Western blotting assay was used to evaluate whether hyperforin-induced apoptosis is associated with inhibition of anti-apoptotic protein expression. Cyclin D1, a proliferative protein, acts as active switch to initiate cell-cycle progression (28). Therefore, we also investigated the effect of hyperforin on expression of cyclin D1 in addition to anti-apoptotic proteins. Figure 4 shows that hyperforin significantly reduced protein levels of c-FLIP, XIAP, MCL1, and cyclin D1 in a time-dependent manner as compared to controls.

\section{Discussion}

Hyperforin, a bioactive compound with antidepressive effect, has been indicated to inhibit tumor growth in breast cancer and myeloid tumor by induction of caspase-mediated apoptosis $(15,16)$. However, whether hyperforin can suppress tumor cell growth through induction of apoptosis in HCC is ambiguous. Therefore, we investigated the antitumor effect and mechanism of hyperforin in HCC SKHep1 cells. To begin with, we found that hyperforin induces cytotoxicity in SK-Hep1 cells (Figure 1). Hyperforin triggers accumulation of cells at sub- $\mathrm{G}_{1}$ phase and increases the level of active caspase-3 (Figure 2). Furthermore, hyperforin elicits loss of MMP and activation of caspase-8 (Figure 3 ). Finally, hyperforin reduces expression of anti-apoptotic and proliferative proteins (c-FLIP, XIAP, MCL1, and cyclin D1).

High expression of anti-apoptotic and proliferative proteins including c-FLIP, XIAP, MCL1, and cyclin D1 is observed in HCC and related to poor prognosis of patients (5-7). Fleischer et al. found increased MCL1 protein 

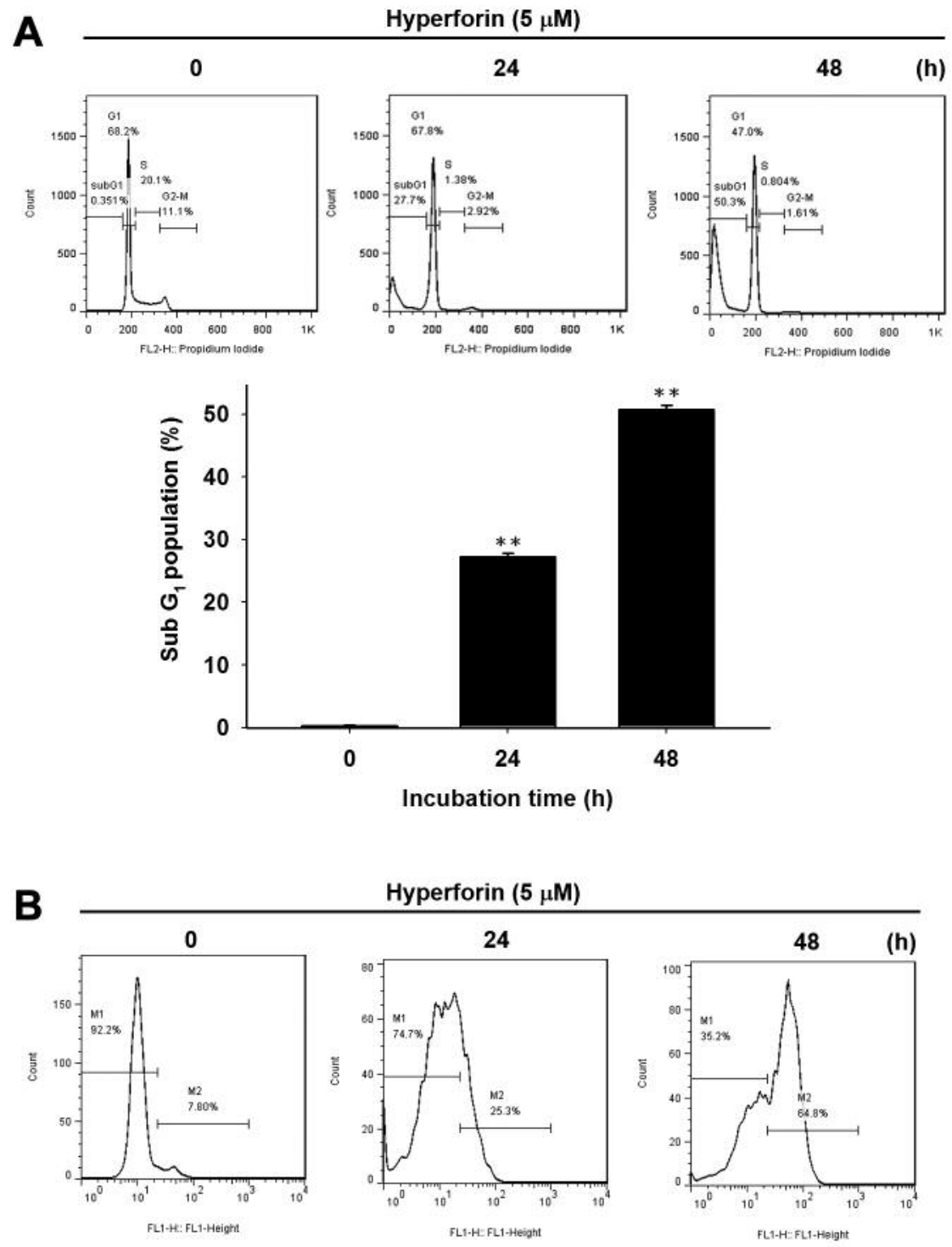

Hyperforin $(5 \mu \mathrm{M})$
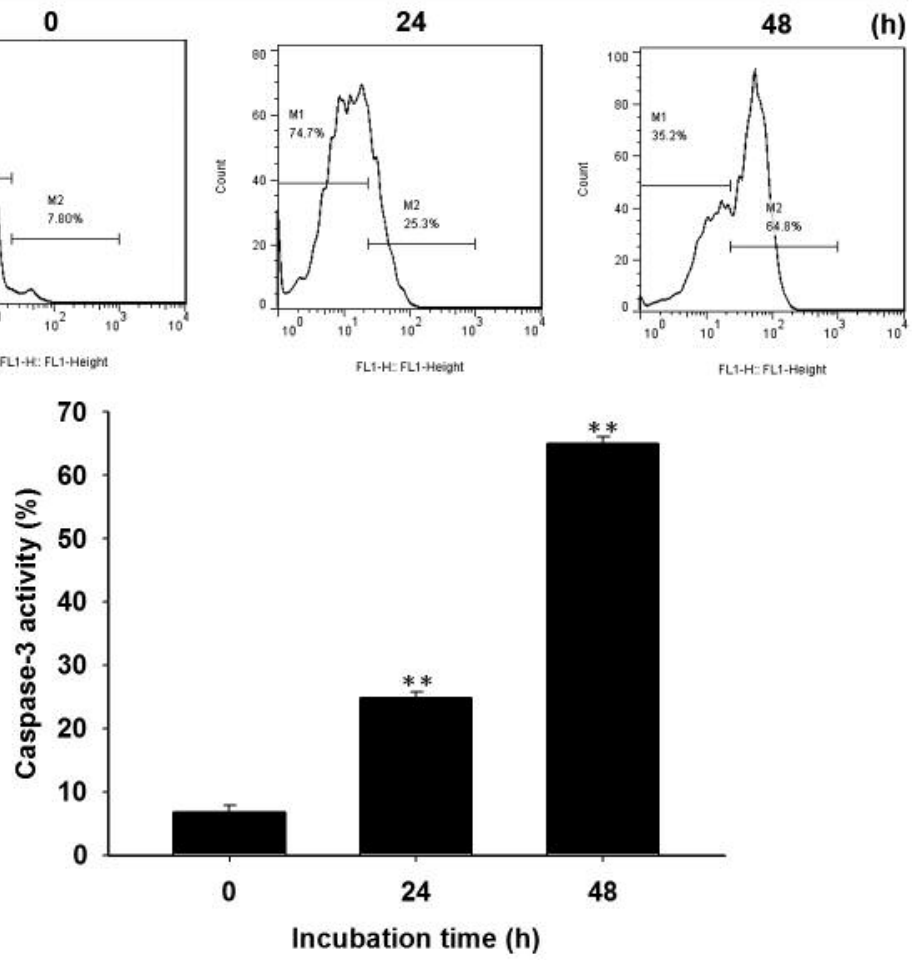

Figure 2. The effects of hyperforin on the sub-G $G_{1}$ population (A) and activation of caspase-3 (B) in SK-Hep1 cells. Cells were treated with $5 \mu M$ hyperforin for 24 and $48 \mathrm{~h}$. Analysis of Sub-G $G_{1}$ population and detection of active caspase-3 was performed by using flow cytometry. **Significantly different at $p<0.01$ compared to controls. 


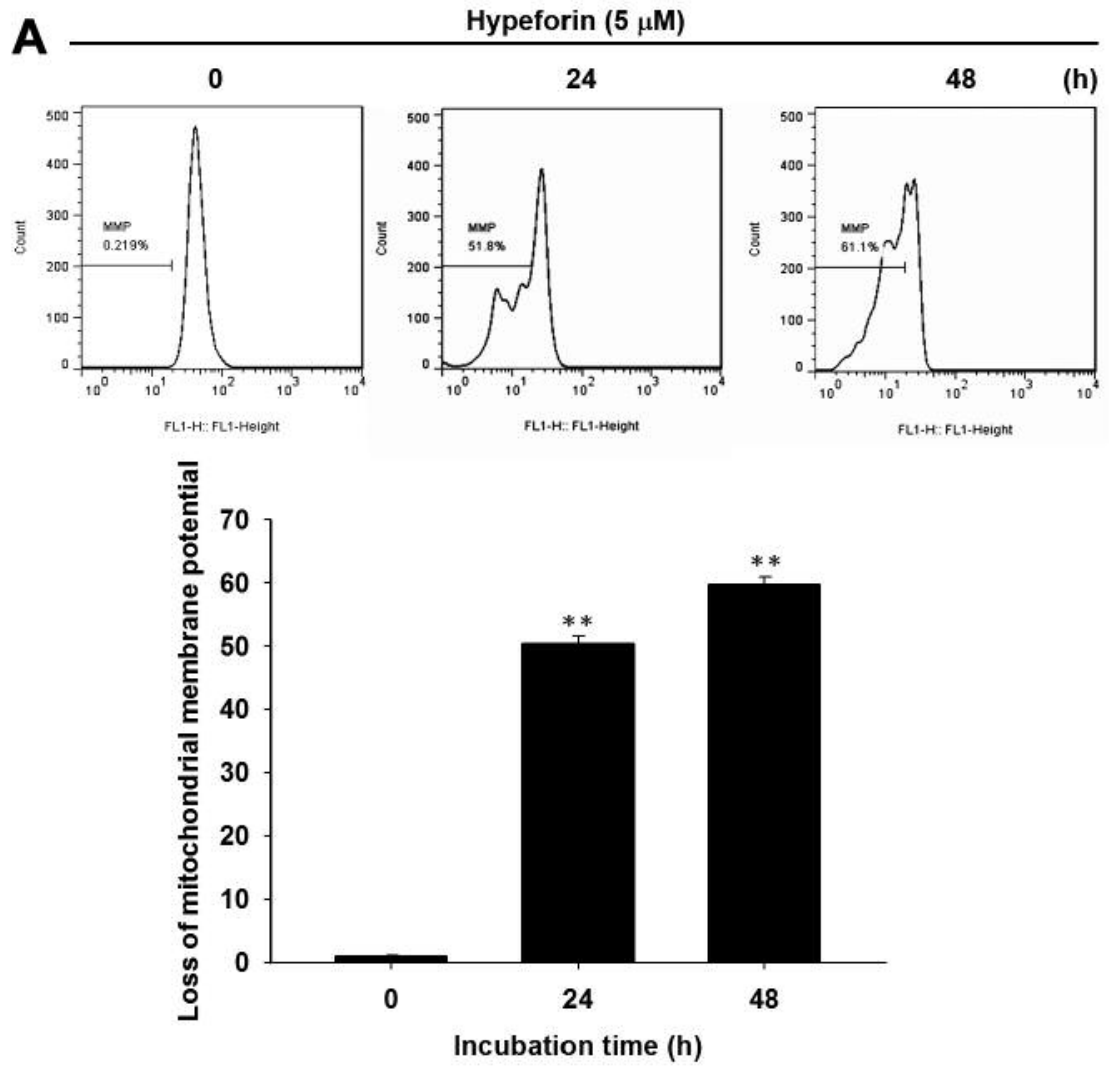

B

Hyperforin $(5 \mu \mathrm{M})$
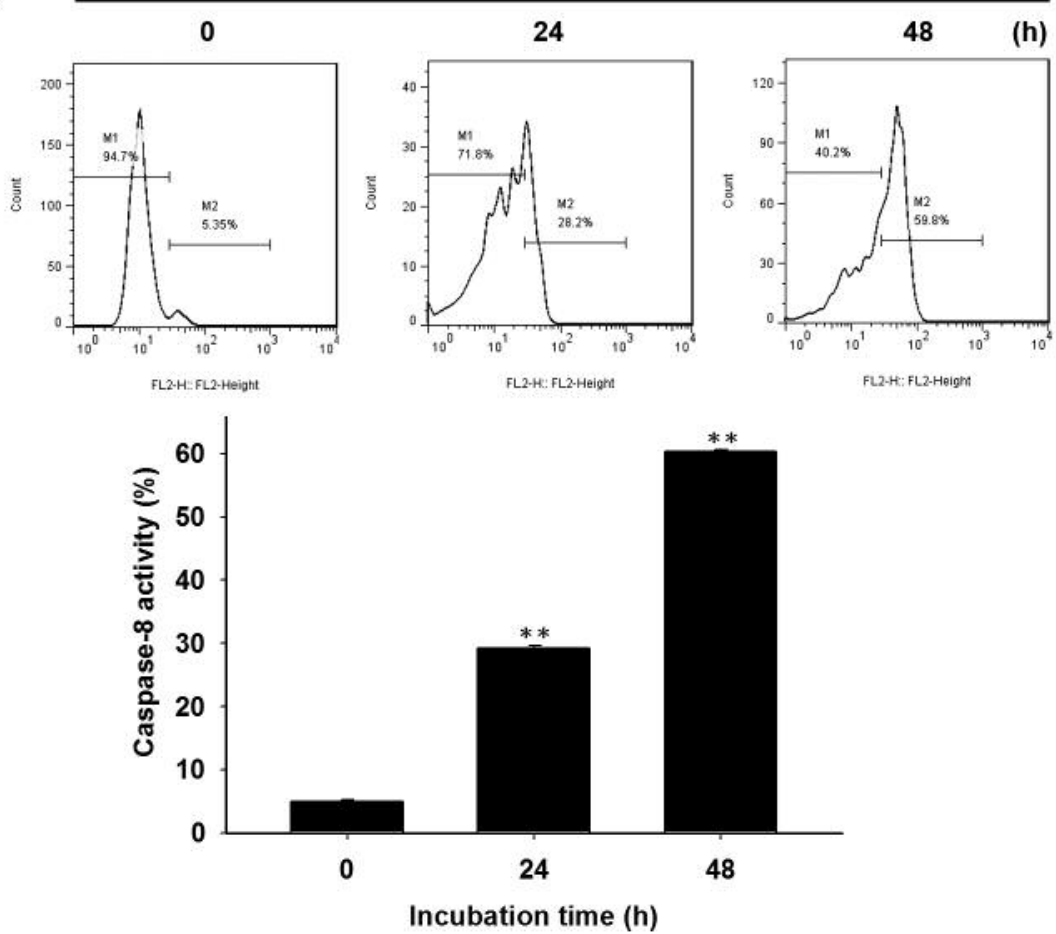

Figure 3. The effects of hyperforin on mitochondrial membrane potential (A) and activation of caspase-8 (B) in SK-Hep1 cells as detected by using flow cytometry. $* *$ Significantly different at $p<0.01$ as compared to controls. 

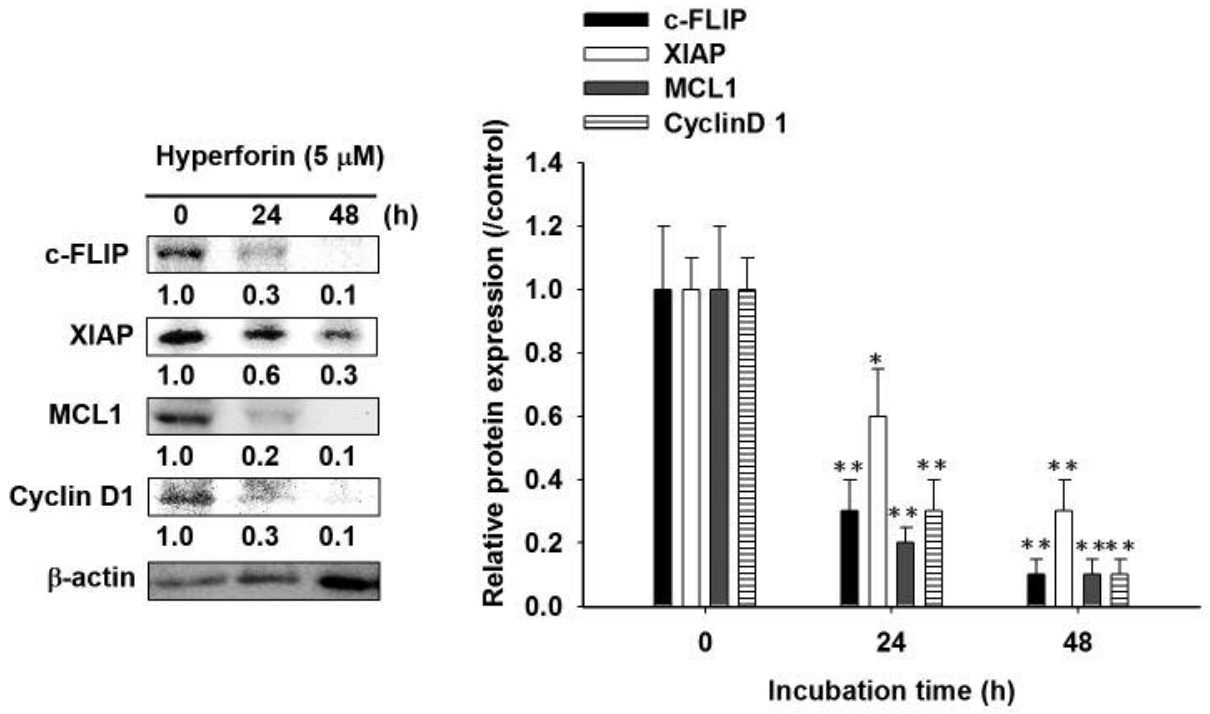

Figure 4. The effects of hyperforin on expression of anti-apoptotic and proliferative proteins in SK-Hep1 cells. Changes of cellular FLICE-like inhibitory protein (c-FLIP), myeloid cell leukemia 1 (MCL1), and X-linked inhibitor of apoptosis protein (XIAP) and cyclin D1 protein. Protein levels were evaluated with western blotting assay. Significantly different at $* p<0.05$ and $* * p<0.01$ as compared to controls.

expression in human HCC tissue compared to adjacent nontumor tissues and suggested that MCL1 is an anti-apoptotic factor for HCC (6). Che et al. found co-expression of XIAP and cyclin D1 proteins correlated with poor prognosis in patients with HCC (7). Du et al. found that overexpression of c-FLIP protein implied a lower probability of recurrencefree survival in patients with $\mathrm{HCC}$ and specific silencing of c-FLIP gene enhanced drug-induced apoptosis of HCC cells (5). Our study results demonstrated that hyperforin significantly reduces expression of c-FLIP, XIAP, MCL1, and cyclin D1 (Figure 4). Merhi et al. found that hyperforin inhibited expression of anti-apoptotic protein B-cell lymphoma 2 (BCL2) in a dose-dependent manner while levels of MCL1 in human myeloid tumor cells appeared to be reduced by hyperforin at a concentration of $2 \mu \mathrm{g} / \mathrm{ml}$ (16). Our data show that $5 \mu \mathrm{M}$ hyperforin suppressed expression of MCL1 protein in a time-dependent manner (Figure 4).

The loss of MMP is required for induction of the intrinsic apoptotic pathway. Apoptotic protein cytochrome $c$, an activator of downstream caspases, is bound to the inner mitochondrial membrane by anionic phospholipid cardiolipin. Cytochrome $c$ released from mitochondria is associated with loss of MMP and initiates intrinsic apoptosis (29). Active caspase- 8 , which modulates activation of caspase- 3 and caspase-7, is essential for induction of extrinsic apoptosis by different death receptors (27). Schempp et al. found loss of MMP and cytochrome $c$ release are enhanced but activation of caspase-8 is not affected by hyperforin (15). Therefore, they suggested that hyperforin induces apoptosis through intrinsic apoptotic pathway in breast carcinoma MT-450 cells. Our results indicated that hyperforin induces both loss of MMP and increase of active caspase-8 in SK-Hep1 cells (Figure 3). We suggest that hyperforin not only inhibits expression of anti-apoptotic and proliferative proteins (cFLIP, XIAP, MCL1, and cyclin D1) but also induces intrinsic and extrinsic apoptosis of SK-Hep1 cells.

In conclusion, this study indicated that hyperforin, as an apoptotic inducer, can inhibit tumor cell growth through induction of intrinsic and extrinsic apoptotic pathways. We propose that hyperforin may be a potential anticancer agent for patients with HCC.

\section{Acknowledgements}

This study was supported by grants RD2016-002 and RD2016-014 from the National Yang-Ming University Hospital, Yilan, Taiwan and Tomorrow Medical Foundation. The Authors acknowledge the technical services provided by Clinical Medicine Research Laboratory of National Yang-Ming University Hospital.

\section{References}

1 Yoshida H, Kong YY, Yoshida R, Elia AJ, Hakem A, Hakem R, Penninger JM and Mak TW: Apaf1 is required for mitochondrial pathways of apoptosis and brain development. Cell 94: 739-750, 1998.

2 Elmore S: Apoptosis: a review of programmed cell death. Toxicol Pathol 35: 495-516, 2007.

3 Pommier Y, Sordet O, Antony S, Hayward RL and Kohn KW: Apoptosis defects and chemotherapy resistance: molecular interaction maps and networks. Oncogene 23: 2934-2949, 2004. 
4 Avila MA, Berasain C, Sangro B and Prieto J: New therapies for hepatocellular carcinoma. Oncogene 25: 3866-3884, 2006.

5 Du X, Bao G, He X, Zhao H, Yu F, Qiao Q, Lu J and Ma Q: Expression and biological significance of c-FLIP in human hepatocellular carcinomas. J Exp Clin Cancer Res 28: 24-31, 2009.

6 Fleischer B, Schulze-Bergkamen H, Schuchmann M, Weber A, Biesterfeld S, Müller M, Krammer PH and Galle PR: MCL-1 is an anti-apoptotic factor for human hepatocellular carcinoma. Int J Oncol 28: 25-32, 2006

7 Che Y, Ye F, Xu R, Qing H, Wang X, Yin F, Cui M, Burstein D, Jiang B and Zhang DY: Co-expression of XIAP and cyclin D1 complex correlates with a poor prognosis in patients with hepatocellular carcinoma. Am J Pathol 180: 1798-1807, 2012.

8 Frick LR and Rapanelli M: Antidepressants: influence on cancer and immunity. Life Sci 92: 525-532, 2013.

9 de Oliveira MR: Fluoxetine and the mitochondria: A review of the toxicological aspects. Toxicol Lett 258: 185-191, 2016.

10 Mun AR, Lee SJ, Kim GB, Kang HS, Kim JS and Kim SJ: Fluoxetine-induced apoptosis in hepatocellular carcinoma cells. Anticancer Res 33: 3691-3697, 2014.

11 Liu KH, Yang ST, Lin YK, Lin JW, Lee YH, Wang JY, Hu CJ, Lin EY, Chen SM, Then CK and Shen SC: Fluoxetine, an antidepressant, suppresses glioblastoma by evoking AMPARmediated calcium-dependent apoptosis. Oncotarget 6: 5088$5101,2015$.

12 Fang CK, Chen HW, Chiang IT, Chen CC, Liao JF, Su TP, Tung CY, Uchitomi Y and Hwang JJ. Mirtazapine inhibits tumor growth via immune response and serotonergicsystem. PLoS One 7: e38886, 2012.

13 Medina MA, Martínez-Poveda B, Amores-Sánchez MI and Quesada AR: Hyperforin: more than an antidepressant bioactive compound. Life Sci 79: 105-111, 2006.

14 Donà M, Dell'Aica I, Pezzato E, Sartor L, Calabrese F, Della Barbera M, Donella-Deana A, Appendino G, Borsarini A, Caniato $\mathrm{R}$ and Garbisa S: Hyperforin inhibits cancer invasion and metastasis. Cancer Res 64: 6225-6232, 2004.

15 Schempp CM, Kirkin V, Simon-Haarhaus B, Kersten A, KissJ, Termeer CC, Gilb B, Kaufmann T, Borner C, Sleeman JP, Simon JC: Inhibition of tumour cell growth by hyperforin, a novel anticancer drug from St. John's wort that acts by induction of apoptosis. Oncogene 21: 1242-1250, 2002.

16 Merhi F, Tang R, Piedfer M, Mathieu J, Bombarda I, Zaher M, KolbJP, Billard C and Bauvois B: Hyperforin inhibits AKT1 kinase activity and promotes caspase-mediated apoptosis involving BAD and NOXA activation in human myeloid tumor cells. PLoS One 6: e25963, 2011.

17 Ma CY, Ji WT, Chueh FS, Yang JS, Chen PY, Yu CC and Chung JG: Butein inhibits the migration and invasion of SK-HEP-1 human hepatocarcinoma cells through suppressing the ERK, JNK, p38 and uPA signaling multiple pathways. J Agric Food Chem 59: 9032-9038, 2011.

18 Chen JH, Chen WL and Liu YC: Amentoflavone induces antiangiogenic and anti-metastatic effects through suppression of NF- $\mathrm{KB}$ activation in MCF-7 cells. Anticancer Res 35: 66856693, 2015.
19 Ma YS, Weng SW, Lin MW, Lu CC, Chiang JH, Yang JS, Lai KC, Lin JP, Tang NY, Lin JG and Chung JG: Antitumor effects of emodin on LS1034 human colon cancer cells in vitro and in vivo: roles of apoptotic cell death and LS1034 tumor xenografts model. Food Chem Toxicol 50: 1271-1278, 2012.

20 Lin SS, Huang HP, Yang JS, Wu JY, Hsia TC, Lin CC, Lin CW, Kuo CL, Gibson Wood W and Chung JG: DNA damage and endoplasmic reticulum stress mediated curcumin-induced cellcycle arrest and apoptosis inhuman lung carcinoma A-549 cells through the activation caspases cascade- and mitochondrialdependent pathway. Cancer Lett 272: 77-90, 2008.

21 Hsu FT, Liu YC, Liu TT and Hwang JJ: Curcumin sensitizes hepatocellular carcinoma cells to radiation via suppression of radiation-induced NF-kB activity. Biomed Res Int 2015: 363671, 2015.

22 Chen TC, Lai KC, Yang JS, Liao CL, Hsia TC, Chen GW, Lin JJ, Lin HJ, Chiu TH, Tang YJ and Chung JG: Involvement of reactive oxygen species and caspase-dependent pathway in berberine-induced cell-cycle arrest and apoptosis in C6 rat glioma cells. Int J Oncol 34: 1681-1690, 2009.

23 Lai KC, Huang AC, Hsu SC, Kuo CL, Yang JS, Wu SH and Chung JG: Benzyl isothiocyanate (BITC) inhibits migration and invasion of human colon cancer HT2 9 cells by inhibiting matrix metalloproteinase-2/-9 and urokinase plasminogen (uPA) through PKC and MAPK signaling pathway. J Agric Food Chem 58: 2935-2942, 2010.

24 Kajstura M, Halicka HD, Pryjma J and Darzynkiewicz Z: Discontinuous fragmentation of nuclear DNA during apoptosis revealed by discrete 'sub-G1' peaks on DNA content histograms. Cytometry A 71: 125-131, 2007.

25 Namura S, Zhu J, Fink K, Endres M, Srinivasan A, Tomaselli KJ, Yuan J and Moskowitz MA: Activation and cleavage of caspase-3 in apoptosis induced by experimental cerebral ischemia. J Neurosci 18: 3659-3668, 1998.

26 Gottlieb E, Armour SM, Harris MH and Thompson CB: Mitochondrial membrane potential regulates matrix configuration and cytochrome $c$ release during apoptosis. Cell Death Differ 10: 709-717, 2003.

27 Kaufmann SH and Earnshaw WC: Induction of apoptosis by cancer chemotherapy. Exp Cell Res 256: 42-49, 2000.

28 Stacey DW: Cyclin D1 serves as cell-cycle regulatory switch in actively proliferating cells. Curr Opin Cell Biol 15: 158-63, 2003.

29 Gogvadze V, Orrenius S and Zhivotovsky B: Multiple pathways of cytochrome $c$ release from mitochondria in apoptosis. Biochim Biophys Acta 1757: 639-647, 2006.
Received November 3, 2016

Revised November 27, 2016

Accepted November 29, 2016 